\title{
One-pot synthesis of 1-azaspiro frameworks initiated by photooxidation of simple furans
}

\author{
Dimitris Kalaitzakis, Eirini Antonatou and Georgios Vassilikogiannakis* \\ Received (in $X X X, X X X)$ Xth $X X X X X X X X X 20 X X$, Accepted Xth $X X X X X X X X X 20 X X$ \\ ${ }_{5}$ DOI: 10.1039/b000000x
}

A range of 1-azaspirocycles, spiroaminals and 1,6diazaspirocycles has been synthesized, starting from simple and readily accessible furan precursors, using a cascade reaction sequence initiated by singlet oxygen.

10 Nitrogen-containing spirocycles of type $\mathbf{D}$ (Scheme 1) represent a very important class of building blocks as the motif exists in an elaborated form in many natural products and pharmaceuticals including Cylindricine $\mathrm{A},{ }^{1 \mathrm{a}}$ Ansalactam $\mathrm{A},{ }^{1 \mathrm{~b}}$ and Grandilodines $\mathrm{A}-\mathrm{C}^{1 \mathrm{c}}$ (for $\mathrm{X}=\mathrm{C}$ ), Marineosins $\mathrm{A}$ and $\mathrm{B},{ }^{2 \mathrm{a}}$ Armeniaspirols $\mathrm{A}-\mathrm{C},{ }^{2 \mathrm{~b}}$ 15 and Kleinhospitines $\mathrm{A}-\mathrm{D}^{2 \mathrm{c}}$ (for $\mathrm{X}=\mathrm{O}$ ) and Pandamarine, ${ }^{3 \mathrm{a}}$ and Haplophytine $^{3 \mathrm{~b}, \mathrm{c}}$ (for $\mathrm{X}=\mathrm{N}$ ).

Out of the known methods for synthesis of 1-azaspirocycles (D, $\mathrm{X}=\mathrm{C}),{ }^{4}$ several proceed via $N$-acyliminium (NAI) formation followed by cyclization with an alkene, or an aromatic $\pi$ 20 nucleophile. ${ }^{6-10}$ However, only one method for the one-step construction of the complete spiro-scaffold (formation of both N1-C5 and C5-C6 bonds of D, Scheme 1), via NAI cyclization, has been reported. ${ }^{7 a, 8}$ This method, beginning from a keto amide, was successfully applied to the synthesis of (-)-Lepadiformine, ${ }^{7 a-}$ ${ }_{25}{ }^{\mathrm{c}}(+)$-Cylindricine $\mathrm{C}^{7 \mathrm{~b}-\mathrm{d}}$ and (-)-Fasicularin ${ }^{7 \mathrm{c}}$ and is similar to a strategy originally developed by Speckamp, ${ }^{6}$ and extended by Vernon ${ }^{10}$ to aromatic $\pi$-nucleophiles.

Fewer general methods concerning the efficient synthesis of spiroaminals $(\mathbf{D}, \mathrm{X}=\mathrm{O})$ have been reported. ${ }^{11}$ An acid-catalyzed $30 \mathrm{NAI}$-formation with subsequent cyclization in order to produce the $o x a$-aza-spirocycle has been reported. ${ }^{12}$ Only one of these examples was performed in one-step and in this case it began from a specific hydroxy-keto-amide as part of efforts directed towards the synthesis of Marineosin A. ${ }^{12 \mathrm{f}}$

35 Reports dealing with the construction of 1,6-diazaspirocycles (D, $\mathrm{X}=\mathrm{N})$ are more limited ${ }^{13}$ and only one example utilizing NAIchemistry has been reported. ${ }^{14}$ Recently, a new method has been developed for the construction of the 1,6-diazaspirocycle of Haplophytine based on a semipinacol-type rearrangement ${ }^{15 a}$ and 40 then applied to the total synthesis of (+)-Haplophytine. ${ }^{15 b, c}$

The investigation described herein focuses on the facile onepot synthesis of all three of the azaspiro-frameworks introduced above (D, Scheme 1). The reaction sequence is initiated by singlet oxygen-mediated oxidation of very simple and easily 45 accessible 2 -substituted furans. ${ }^{16}$ The one-pot protocol begins with the formation of 2-pyrrolidinone $\mathbf{B},{ }^{17}$ an intermediate which is then protonated in situ to yield an NAI $\mathbf{C}$ that is attacked by a pendant nucleophile to furnish the final spirocycle $\mathbf{D}$ (Scheme 1).

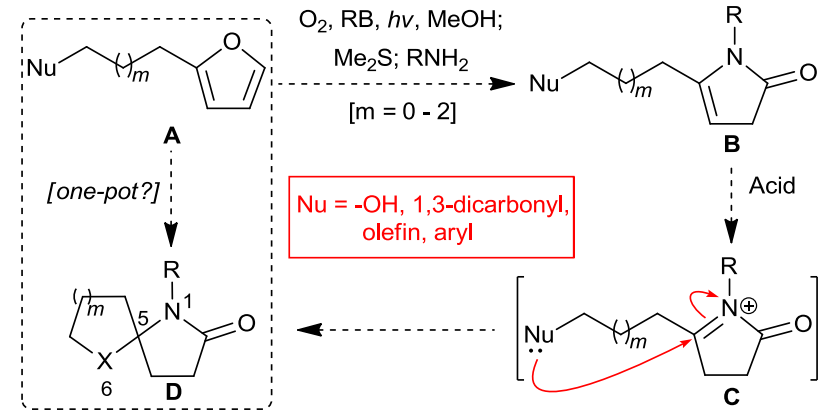

50 Scheme 1 General concept for the synthesis of 1-azaspirocyclic lactams.

The investigation began with simple 2 -( $\gamma$-hydroxyalkyl) and 2( $\delta$-hydroxyalkyl) furans as substrates $(\mathbf{1}$, Scheme 2$)$. Irradiation of a solution of these furans (in $\mathrm{MeOH}$ containing $10^{-4} \mathrm{M}$ rose Bengal and with oxygen gently bubbling through it) with visible 55 light for $8 \mathrm{~min}$, followed by treatment with 4 eq of dimethyl sulfide (DMS) and 0.9 eq of an amine (2), resulted in the formation of the intermediate 2-pyrrolidinone ${ }^{17}$ (3, Scheme 2). Treatment of this 2-pyrrolidinone $\mathbf{3}$ with a Brønsted acid (TFA or
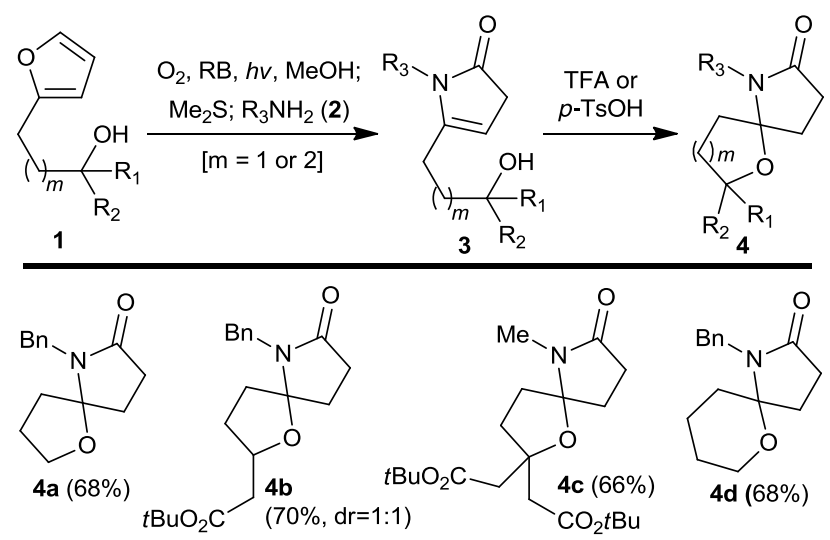

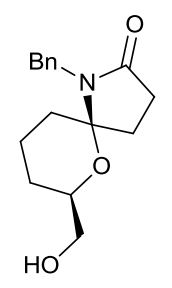

4 e $(70 \%)$
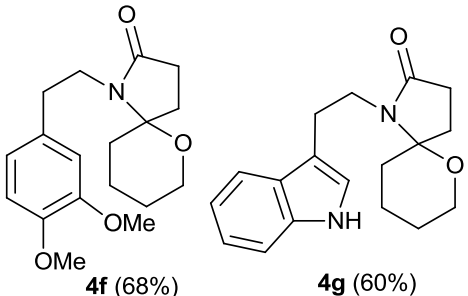

4g $(60 \%)$

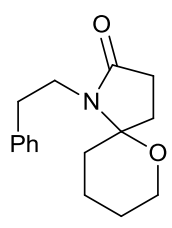

4h $(64 \%)$
60 Scheme 2 One-pot synthesis of spiroaminals starting from simple furans. 


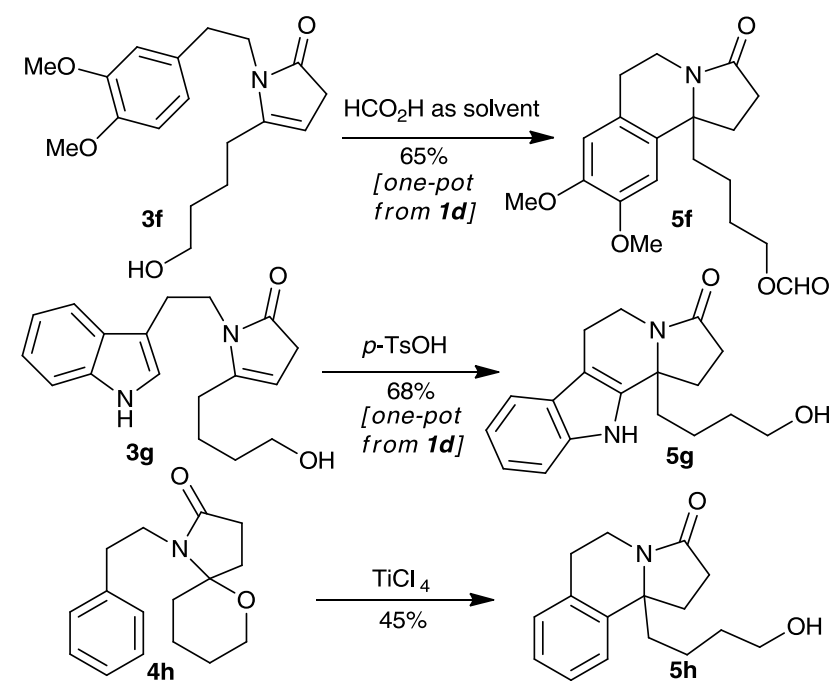

Scheme 3 Pictet-Spengler cyclization to fused bicyclic lactams.

$p$-TsOH) followed by 5-exo, or 6-exo cyclization, of the intermediate NAI of type $\mathbf{C}$ (Scheme 1) led to the exclusive 5 formation of both [5,5]- (4a-c) and [5,6]-spiroaminals (4d-h, Scheme 2) in $60-70 \%$ isolated yield. $p$-TsOH (0.2 eq) was found to be more suitable in the case of [5,6]-spiroaminal $\mathbf{4 e}$ (isolated as single diastereoisomer) because the free hydroxy group of the final product could easily be esterified with TFA.

10 Following the successful synthesis of spiroaminals $\mathbf{4 f - h}$ (Scheme 2) using amines of type $\mathrm{ArCH}_{2} \mathrm{CH}_{2} \mathrm{NH}_{2}$ each bearing an aromatic unit with a different degree of nucleophilicity (a phenyl ring activated by two methoxy substituents in $\mathbf{4 f}$, an indole ring in $\mathbf{4 g}$ and a simple phenyl ring in $\mathbf{4 h}$ ), our investigation moved on to 15 examination of the possibility of a 6-endo cyclization with the amine's aromatic ring (Pictet-Spengler ${ }^{18}$ aromatic substitution, Scheme 3) of intermediates $\mathbf{3 f}-\mathbf{h}$ by adjusting the type and the amount of the acid used. In particular, by adding either $\mathrm{HCOOH}$ (as solvent), or $p$-TsOH $(0.4 \mathrm{eq})$, the Pictet-Spengler cyclization 20 was achieved furnishing exclusively the corresponding fused bicyclic lactams $\mathbf{5 f}$ and $\mathbf{5 g}$ (Scheme 3). It is important to mention here that both these reactions were performed as one-pot processes starting from furan $\mathbf{1 d}\left(m=2, R_{1}=R_{2}=H\right.$, Scheme 2). Moreover, if isolated, [5,6]-spiroaminals $\mathbf{4 f}$ and $\mathbf{4 g}$ could be 25 exclusively transformed to the corresponding fused bicyclic lactams $\mathbf{5 f}$ and $\mathbf{5 g}$ if treated with $\mathrm{HCOOH}$ (as solvent), or $p$ $\mathrm{TsOH}(0.4 \mathrm{eq})$, respectively. For the formation of bicyclic lactam $\mathbf{5 h}$, isolation of spiroaminal $\mathbf{4 h}$ was necessary before treatment with $\mathrm{TiCl}_{4}$ (3.0 eq, Scheme 3). ${ }^{19}$

30 Exploration of different nucleophiles appended to the 2-alkyl side chain of the starting furans was next investigated with the aim of preparing of 1-azaspirocycles $(\mathbf{D}, \mathrm{X}=\mathrm{C}$, Scheme 1). For this purpose, three alternative types of cyclizations (PictetSpengler, ${ }^{18} a z a$-Prins ${ }^{20}$ and Mannich $^{21}$ ) for the final stage of this 35 one-pot process were studied. Furans 6, 8 and 11 (Scheme 4) were selected, bearing different nucheophiles on the 2-alkyl side chain (a phenyl ring, an olefin and a $\beta$-ketoester, respectively). Application of the developed protocol to furan 6 using $\mathrm{AlCl}_{3}$ as the Lewis acid, afforded the Pictet-Spengler product 7 (Scheme 404 ). In the case of furan $\mathbf{8}$, two different azaspirocycles were obtained through an aza-Prins cyclization by tailoring the choice of acid at the final stage of the one-pot process. Use of $\mathrm{HCOOH}$
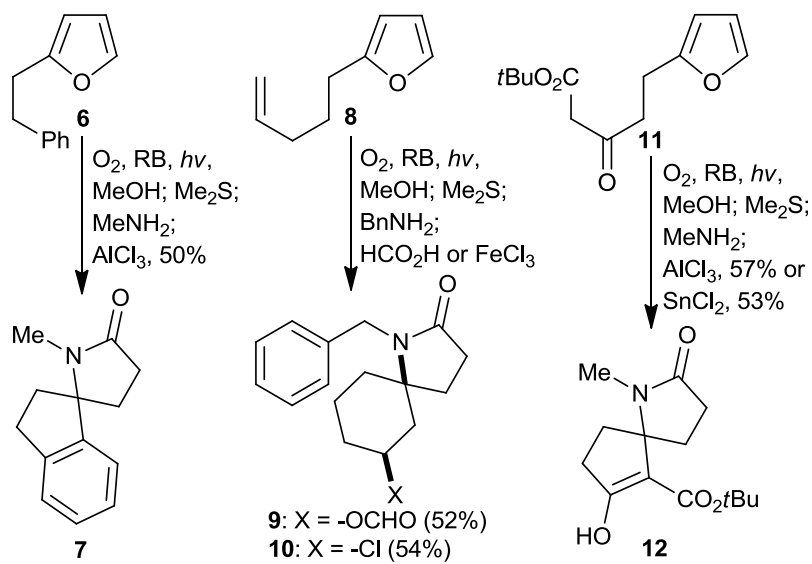

Scheme 4 One-pot synthesis of various 1-azaspirocycles.

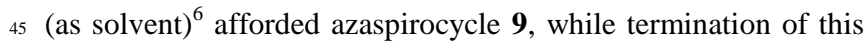
one-pot process with $\mathrm{FeCl}_{3}(2.0 \mathrm{eq})^{22}$ gave azaspirocycle 10. Both azaspirocycles $\mathbf{9}$ and $\mathbf{1 0}$ were obtained as single diastereoisomers (Scheme 4). $\mathrm{SnCl}_{4}$ mediated aza-Prins cyclization was also attempted, but a mixture of regioisomers of $\mathbf{1 0}$ was isolated; this 50 observation is in agreement with a previously reported one applying to a similar situation, but where $\mathrm{TiCl}_{4}$ is used as the Lewis acid. ${ }^{9 \mathrm{~b}}$ Finally, $\beta$-ketoester $\mathbf{1 1}$ was employed for the formation of the [5,5]-1-azaspirocycle 12 through a Mannich cyclization. The reaction proceeded smoothly leaving the 55 sensitive $\beta$-ketoester group untouched through the early stages of this complex cascade reaction sequence producing the intermediate 2-pyrrolidinone of type $\mathbf{B}$ (Scheme 1). Since Brønsted acid-mediated Mannich cyclizations are known to be difficult, $^{7 \mathrm{~d}}$ efforts were focused on employing Lewis acidic 60 conditions. After intensive screening $\left(\mathrm{TiCl}_{4}\right.$ in the presence of $\mathrm{AcOH}^{23}$ does not give reproducible results), $\mathrm{AlCl}_{3}$ (2.0 eq) and $\mathrm{SnCl}_{2}(3.5 \mathrm{eq})$ were found to be the best Lewis acids for the formation of the desired compound $\mathbf{1 2}$.

Finally, our focus shifted to the construction of 1,6${ }_{65}$ diazaspirocycles (16a,b Scheme 5). As free amines are sensitive to singlet oxygen-photooxygenation conditions, ${ }^{24}$ the application of the developed protocol to a furan of type $\mathbf{A}$ (Scheme 1) where $\mathrm{Nu}=-\mathrm{NHR}$, was not a viable option. Instead, the intermolecular attack of a second amine on to the NAI arising from 270 pyrrolidinones 14a,b and a subsequent intramolecular substitution of an iodide at $\gamma$-, or $\delta$-positions, of the alkyl side chain of intermediates 15a,b (Scheme 5) was investigated. This idea was successfully applied to iodo-furans $\mathbf{1 3 a}$ and $\mathbf{1 3 b},{ }^{19}$ using
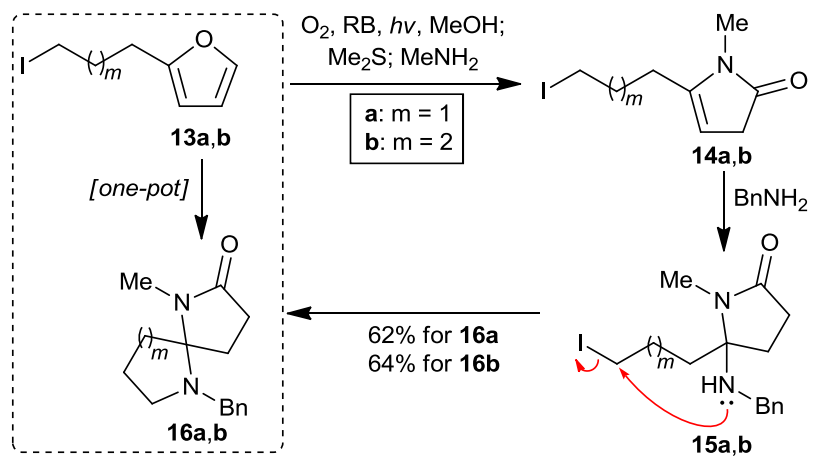

75 Scheme 5 One-pot synthesis of 1,6-diazaspirocycles. 
$\mathrm{MeNH}_{2}$ for the formation of 2-pyrrolidinones $\mathbf{1 4 a}, \mathbf{b}$, followed by addition of a second amine $\left(\mathrm{BnNH}_{2}\right)$ in refluxing chloroform. The desired [5,5]- and [5,6]-1,6-diazaspirocycles 16a,b were isolated. The total yields for these processes $(62 \%$ for $\mathbf{1 6 a}$ and $64 \%$ for 5 16b) are remarkable if the intricate nature of the cascade reaction sequence that leads to their formation is taken into account. Crude ${ }^{1} \mathrm{H}$ NMR spectra, taken before completion of the final step $(15 \mathbf{a} \rightarrow \mathbf{1 6 a})$ of this one-pot sequence, revealed the formation of intermediate 15a, suggesting that the proposed sequence of 10 events (initial formation of $\mathbf{1 5 a}, \mathbf{b}$ followed by the intramolecular nucleophilic substitution of the primary iodide) is indeed correct.

We have developed a practical and highly controllable one-pot reaction sequence for the synthesis of a variety of different 1azaspiro frameworks, including 1-azaspirocycles, spiroaminals 15 and 1,6-diazaspirocycles. The reaction sequence is initiated by singlet oxygen-mediated oxidation of simple and readily accessible furans. This novel technology answers the call for new sustainable processes from a number of different perspectives; namely, a dramatic increase in molecular complexity in one 20 synthetic operation has been achieved, protecting groups are not required and the oxidant is metal- and toxic residue-free. In addition, singlet oxygen is generated using benign conditions and its employment maximizes atom-economy.

The research leading to these results has received funding from 25 the European Research Council under the European Union's Seventh Framework Programme (FP7/2007-2013)/ERC Grant Agreement No. 277588.

\section{Notes and references}

Department of Chemistry, University of Crete, 71003 Iraklion, Crete, 30 Greece. Fax: +302810 545001; Tel: +30 2810 545074; E-mail:

vasil@chemistry.uoc.gr

$\dagger$ Electronic Supplementary Information (ESI) available: [Experimental procedures, full spectroscopic data and copies of ${ }^{1} \mathrm{H}$ and ${ }^{13} \mathrm{C}$ NMR spectra for all new compounds, as well as copies of the NOE experiments]. See 35 DOI: $10.1039 / \mathrm{b} 000000 \mathrm{x} /$

1 (a) A. J. Blackman, C. Li, Tetrahedron 1993, 49, 8645; (b) M. C. Wilson, S.-J. Nam, T. A. M. Gulder, C. A. Kauffman, P. R. Jensen, W. Fenical, B. S. Moore, J. Am. Chem. Soc. 2011, 133, 1971; (c) W.-

40 S, Yap, C.-Y. Gan, Y.-Y. Low, Y.-M. Choo, T. Etoh, M. Hayashi, K. Komiyama, T.-S. Kam, J. Nat. Prod. 2011, 74, 1309.

2 (a) C. Boonlarppradab, C. A. Kauffman, P. R. Jensen, W. Fenical, Org. Lett. 2008, 10, 5505; (b) C. Dufour, J. Wink, M. Kurz, H. Kogler, H. Olivan, S. Sablé, W. Heyse, M. Gerlitz, L. Toti, A. Nußer,

45 A. Rey, C. Couturier, A. Bauer, M. Brönstrup, Chem. Eur. J. 2012, 18, 16123; (c) C.-X. Zhou, L. Zou, L.-S. Gan, Y.-L. Cao, Org. Lett. 2013, 15, 2734.

3 (a) L. T. Byrne, B. Q. Guevara, W. C. Patalinghug, B. V. Recio, C. R. Ualat, A. H. White, Aust. J. Chem. 1992, 45, 1903; (b) E. F.

50 Rogers, H. R. Snyder, R. F. Fischer, J. Am. Chem. Soc. 1952, 74, 1987; (c) P. Yates, F. N. MacLachlan, I. D. Rae, M. Rosenberger, A. G. Szabo, C. R. Willis, M. P. Cava, M. Behforouz, M. V. Lakshmikantham, W. Zeiger, J. Am. Chem. Soc. 1973, 95, 7842.

4 For a review, see: (a) G. Dake, Tetrahedron 2006, 62, 3467 and

55 references therein. For representative examples dealing with the formation of N1-C5 or C5-C6 bond at spirocyclization step see: $(b)$ L. Caggiano, J. Davies, D. J. Fox, D. C. Moody, S. Warren, Chem. Commun. 2003, 39, 1648; (c) T. J. Donohoe, C. K. A. Callens, A. L. Thompson, Org. Lett. 2009, 11, 2305; (d) C. M. Griffiths-Jones, D.

60 W. Knight, Tetrahedron 2010, 66, 4150; (e) H. Liang, M. A. Ciufolini, Chem. Eur. J. 2010, 16, 13262; (f) M. Fujitani, M. Tsuchiya, K. Okano, K. Takasu, M. Ihara, H. Tokuyama, Synlett 2010, 822; ( g) L. I. Palmer, J. Read de Alaniz, Angew. Chem. Int. Ed.
2011, 50, 7167; (h) M. Puppala, A. Murali, S. Baskaran, Chem. Commun. 2012, 48, 5778; (i) M. A. Perry, R. R. Hill, S. D. Rychnovsky, Org. Lett. 2013, 15, 2226; (j) M.-C. P. Yeh, C.-J. Liang, C.-Y. Liu, Y. Shih, I-C. Lee, H.-F. Liu, J.-L. Wang, Org. Biomol. Chem. 2013, 11, 3393; (k) K.-J. Xiao, J.-M. Luo, X.-E. Xia, Y. Wang, P.-Q. Huang, Chem. Eur. J. 2013, 19, 13075.

705 (a) W. N. Speckamp, H. Hiemstra, Tetrahedron 1985, 41, 4367; (b) B. E. Maryanoff, H.-C. Zhang, J. H. Cohen, I. J. Turchi, C. A Maryanoff, Chem. Rev. 2004, 104, 1431.

6 (a) H. E. Schoemaker, W. N. Speckamp, Tetrahedron Lett. 1978, 19 1515; (b) H. E. Schoemaker, W. N. Speckamp, Tetrahedron 1980, 36, 951 .

7 (a) H. Abe, S. Aoyagi, C. Kibayashi, Angew. Chem. Int. Ed. 2002, 41, 3017; (b) J. Liu, R. P. Hsung, S. D. Peters, Org. Lett. 2004, 6 3989; (c) H. Abe, S. Aoyagi, C. Kibayashi, J. Am. Chem. Soc. 2005, 127, 1473; (d) J. Liu, J. J. Swidorski, S. D. Peters, R. P. Hsung, J. Org. Chem. 2005, 70, 3898.

8 H. Abe, K. Takaya, K. Watanabe, S. Aoyagi, C. Kibayashi, T. Katoh, Heterocycles 2007, 74, 205.

9 (a) P. Sun, C. Sun, S. M. Weinreb, Org. Lett. 2001, 3, 3507; (b) T. Ito, N. Yamazaki, C. Kibayashi, Synlett 2001, 1506.

8510 (a) P. D. Bailey, K. M. Morgan, D. I. Smith, J. M. Vernon, Tetrahedron Lett. 1994, 35, 7115; (b) P. D. Bailey, K. M. Morgan, D. I. Smith, J. M. Vernon, Tetrahedron 2003, 59, 3369; (c) A. A. Bahajaj, M. H. Moore, J. M. Vernon, Tetrahedron 2004, 60, 1235.

11 For a review, see: (a) M.-E. Sinibaldi, I. Canet, Eur. J. Org. Chem. 90 2008, 4391 and references therein; $(b)$ A. Y. Sukhorukov, A. V. Lesiv, Y. A. Khomutova, S. L. Ioffe, Y. V. Nelyubina, Synthesis 2008, 1205; (c) J. Robertson, A. J. Tyrrell, P. T. Chovatia, S. Skerratt, Tetrahedron Lett. 2009, 50, 7141; (d) E. L. Cropper, A.-P. Yuen, A. Ford, A. J. P. White, K. K. Hii, Tetrahedron 2009, 65, 525; (e) A. Martín, I. Pérez-Martín, E. Suárez, Tetrahedron 2009, 65, 6147; (f) X.-C. Cai, X. Wu, B. B. Snider, Org. Lett. 2010, 12, 1600; (g) A. P. J. Pal, P. Kadigachalam, A. Mallick, V. R. Doddi, Y. D. Vankar, Org. Biomol. Chem. 2011, 9, 809.

12 (a) F. C. Uhle, F. Sallmann, J. Am. Chem. Soc. 1960, 82, 1190; (b) A. 100 S. Kende, J. I. M. Hernando, J. B. J. Milbank, Org. Lett. 2001, 3, 2505; (c) J.-F. Zheng, W. Chen, S.-Y. Huang, J.-L. Ye, P.-Q. Huang, Beilstein J. Org. Chem. 2007, 3, 1:41; (d) J. D. Panarese, L. C. Konkol, C. B. Berry, B. S. Bates, L. N. Aldrich, C. W. Lindsley, Tetrahedron Lett. 2013, 54, 2231; (e) G. Li, X. Zhang, Q. Li, P. Feng, Y. Shi, Org. Biomol. Chem. 2013, 11, 2936; (f) L. N. Aldrich, C. B. Berry, B. S. Bates, L. C. Konkol, M. So, C. W. Lindsley, Eur. J. Org. Chem. 2013, 4215.

13 (a) K. H. Büchel, A. K. Bocz, F. Korte, Chem. Ber. 1966, 99, 724; (b) O. Tsuge, H. Watanabe, K. Masuda, M. M. Yousif, J. Org. Chem. 1979, 44, 4543.

14 M. J. Martín-López, F. Bermejo, Tetrahedron 1998, 54, 12379.

15 (a) K. Matsumoto, H. Tokuyama, T. Fukuyama, Synlett 2007, 3137; (b) H. Ueda, H. Satoh, K. Matsumoto, K. Sugimoto, T. Fukuyama, H. Tokuyama, Angew. Chem. Int. Ed. 2009, 48, 7600; (c) K. C. 115 Nicolaou, S. M. Dalby, S. Li, T. Suzuki, D. Y.-K. Chen, Angew. Chem. Int. Ed. 2009, 48, 7616.

16 B. König, Science of Synthesis 2000, 9, 183.

17 For generation of 2-pyrrolidinone $\mathbf{B}$ via photooxidation of 2substituted furans, see: (a) D. Kalaitzakis, T. Montagnon, I. Alexopoulou, G. Vassilikogiannakis, Angew. Chem., Int. Ed. 2012, 51, 8868; (b) D. Kalaitzakis, T. Montagnon, E. Antonatou, N. Bardají, G. Vassilikogiannakis, Chem. Eur. J. 2013, 19, 10119; (c) D. Kalaitzakis, T. Montagnon, E. Antonatou, G. Vassilikogiannakis, Org. Lett. 2013, 15, 3714.

12518 (a) A. Pictet, T. Spengler, Ber. Dtsch. Chem. Ges. 1911, 44, 2030; (b) E. D. Cox, J. M. Cook, Chem. Rev. 1995, 95, 1797.

19 See Supporting Information for full details.

20 For a review, see: C. Olier, M. kaafarani, S. Gastaldi, M. P. Bertrand, Tetrahedron 2010, 66, 413.

13021 J. Royer, M. Bonin, L. Micouin, Chem. Rev. 2004, 104, 2311.

22 R. M. Carballo, M. A. Ramírez, M. L. Rodríguez, V. S. Martín, J. I. Padrón, Org. Lett. 2006, 8, 3837.

23 Y. Koseki, H. Sato, Y. Watanabe, T. Nagasaka, Org. Lett. 2002, 4, 885 . 
24 (a) R. S. Davidson, K. R. Trethewey, J. Chem. Soc., Perkin Trans. 2 1977, 173; ibid 178; (b) E. Baciocchi, T. Del Giacco, O. Lanzalunga, A. Lapi, J. Org. Chem. 2007, 72, 9582; (c) G. Jiang, J. Chen, J.-S. Huang, C.-M. Che, Org. Lett. 2009, 11, 4568. 